\title{
Article \\ Cr (III) Removal Capacity in Aqueous Solution in Relation to the Functional Groups Present in the Orange Peel (Citrus sinensis)
}

\author{
Laura Patiño-Saldivar ${ }^{1}$, José A. Hernández ${ }^{1} \mathbb{D}$, Alba Ardila ${ }^{2}$, Mercedes Salazar-Hernández ${ }^{3}$, Alfonso Talavera ${ }^{4}$ (D) \\ and Rosa Hernández-Soto ${ }^{1, *}$
}

Citation: Patiño-Saldivar, L. Hernández, J.A.; Ardila, A.; Salazar-Hernández, M.; Talavera, A.; Hernández-Soto, R. Cr (III) Removal Capacity in Aqueous Solution in Relation to the Functional Groups Present in the Orange Peel (Citrus sinensis). Appl. Sci. 2021, 11, 6346 https://doi.org/10.3390/app11146346

Academic Editors: Angeles

Sanroman Braga and Emilio Rosales Villanueva

Received: 30 April 2021

Accepted: 2 July 2021

Published: 8 July 2021

Publisher's Note: MDPI stays neutral with regard to jurisdictional claims in published maps and institutional affiliations.

Copyright: (c) 2021 by the authors. Licensee MDPI, Basel, Switzerland. This article is an open access article distributed under the terms and conditions of the Creative Commons Attribution (CC BY) license (https:/ / creativecommons.org/licenses/by/ $4.0 /)$.
1 Department of Comprehensive and Institutional Training, Academy of Biotechnology and Pharmacy, UPIIG_Unidad Profesional Interdisciplinaria de Ingeniería Campus Guanajuato, Instituto Politécnico Nacional, Guanajuato 36275, Mexico; patinio0321@gmail.com (L.P.-S.); jahernandezma@ipn.mx (J.A.H.)

2 Jaime Isaza Cadavid Colombian Polytechnic, Medellín 4932, Colombia; anardila@elpoli.edu.co

3 Department of Mining Engineering, Metallurgy and Geology, Engineering Division, University of Guanajuato, Guanajuato 36025, Mexico; merce@ugto.mx

4 Unit of Chemical Sciences, Campus UAZ XXI Century, University of Zacatecas, Zacatecas 98160, Mexico; talavera@uaz.edu.mx

* Correspondence: rohernandezs@ipn.mx; Tel.: +52-5729-6000 (ext. 81416)

\begin{abstract}
Bioremediation is a pollutant removal method that has had a great boom due to the diversity of agroindustrial waste that can be used for this purpose, and that has shown having great efficiency and profitability in the adsorption of heavy metals, such as $\mathrm{Pb}, \mathrm{Cu}$, and $\mathrm{Co}$. Based on the above, the present work carried out kinetic and equilibrium studies of bioadsorption of $\mathrm{Cr}$ (III) using orange peel (OP) as adsorbent, previously treated with methanol, water, and a water-methanol mixture at different $\mathrm{pH}(0.91,1.78$ and 2.72$)$, and at $30^{\circ} \mathrm{C}$, finding that the adsorption capacity at equilibrium increases with increasing $\mathrm{pH}$, having a maximum of $55 \mathrm{mg} \mathrm{g}^{-1}$ at $\mathrm{pH} 2.72$ - under these conditions, lower adsorption energy was used to remove $\mathrm{Cr}$ (III). In addition, it was determined that there are no external mass transfer limitations. An isoelectric point analysis indicated that the adsorption is not carried out by electrostatic forces and a FTIR study of the functional groups of OP showed a decrease in the main functional groups (pectin, cellulose, and lignin, among others), which is directly related to the adsorption capacity of the bioadsorbent.
\end{abstract}

Keywords: bioadsorption; orange peel; removal; functional groups; mass transfer

\section{Introduction}

In recent decades many causes have contributed to the contamination of drinking water, causing this resource to be increasingly scarce; anthropogenic activities, population growth, and poor management of natural water resources, among other factors, have led to a serious crisis, reflected by the insufficiency of water for approximately half of the world's population [1-6]. Additionally, the presence of dyes, various chemical compounds, and heavy metals, which are highly toxic in the waters of lakes, rivers, sewers, etc., have caused serious public health problems. Since these pollutants, and particularly the metals, have a high mobility in the environment, and as they are not naturally biodegraded, they accumulate in bodies of water and are transferred to living beings, which are part of the food chain, allowing these metals to enter the human body and causing cardiovascular, nervous system, and kidney problems, structural alterations in erythrocyte membranes, among other conditions [1-4,6-10].

$\mathrm{Cr}$ (III) is considered an essential trace element for glucose metabolism in living beings; however, in amounts greater than $30 \mathrm{ppm}$, it can be considered dangerous to health [4,6,9-12]. Basic chromium sulfate $\left(2 \mathrm{Cr}(\mathrm{OH}) \mathrm{SO}_{4} \times \mathrm{Na}_{2} \mathrm{SO}_{4}\right)$ is used in many industrial processes, such as leather tanning, an activity that takes place in many developing countries $[6,9,12]$ and which represents a notable pollution problem, due to the inadequate 
treatment of effluents that contain large amounts of Cr. As such, it is necessary to find alternatives to be able to dump these wastes without the presence of this metal [1,6]; there are currently some technologies that stand out in eliminating $\mathrm{Cr}$ (III) from wastewater, such as chemical precipitation, ion exchange, peroxidation, coagulation, membrane filtration, and photocatalytic degradation, among others. These methods, however, are characterized by their high operating costs and maintenance; in addition, some of them generate waste in the form of sludge, which implies a significant economic cost to its disposal $[1,3,7,8,12]$.

On the other hand, bioadsorption is an ecological, versatile, simple, and economical method due to the use of peel residues from various fruits, vegetables, and plants, among others, which, if not handled properly, can also contaminate the environment where they are deposited; therefore, this alternative allows the reuse of waste by incorporating multiple advantages, such as their wide availability, simple treatments, biodegradable capacity, variety of sources, reduction of pollution, and waste management, as well as their high efficiency in the elimination of pollutants, such as heavy metals $[1,3,10,12]$. Bioadsorbents are modified both physically and chemically to improve adsorption capacity, this can be done with milling operations, heat treatment, treatment with basic solvents, acids, and oxidizing agents, among others $[3,9,10,13-15]$.

Some agro-industrial wastes may be suitable candidates for the elimination of $\mathrm{Cr}$ (III), which represents a significant operating cost in industrial processes; as such, there is an economic interest in its recovery from wastewater $[9,11,16,17]$. Among these candidates, the case of the orange peel stands out, which, due to its low cost and high content of organic compounds (pectin, cellulose, hemicellulose, among others) on its surface, along with a large amount of soluble compounds, requires a treatment that allows conditioning the biomaterial and obtaining an increase in its adsorption capacity [16-21]. The orange peel that is discarded by the citrus-processing industry is characterized as having a high contaminating power, given its high content of moisture and fermentable sugars, low $\mathrm{pH}$, and high content of organic matter, which gives it a high rate of fermentability, causing serious economic and environmental problems for its disposal. In addition, this residue can cause soil contamination in cases of direct disposal, water pollution due to the infiltration of putrefactive residues in the water table, and air pollution due to the uncontrolled production of greenhouse gases. Consequently, the use of orange peel as a bioadsorbent material can be beneficial for the environment both by reducing waste without treatment and its effect of metal recovery.

In this work, the removal of $\mathrm{Cr}$ (III) was studied using orange peel (OP) modified with water (WTOP), with methanol (MTOP) and a methanol-water mixture (OPTmW) to know the effect of the modification of the surface of the OP, along with any change in the $\mathrm{pH}$ of the solution and the amount of bioadsorbent. Different models were analyzed in equilibrium and with respect to time to determine the mechanisms with which the adsorption process takes place. Studies were also carried out to know if the external and internal mass transfer intervene directly in the process of elimination of $\mathrm{Cr}$ (III) in aqueous solution; subsequently, regeneration of the $\mathrm{OP}$ was carried out to determine the amount of $\mathrm{Cr}$ that can be recovered by its reuse.

\section{Materials and Methods}

\subsection{Reagents}

All reagents used were of analytical grade. Deionized water was used to prepare the test solutions at 0 to $1000 \mathrm{ppm}$ concentrations. Chromium salt $\left(2 \mathrm{Cr}(\mathrm{OH}) \mathrm{SO}_{4} \times \mathrm{Na}_{2} \mathrm{SO}_{4}\right)$, was donated by the company Cuero Centro (León, México), S.A. de C.V.

\subsection{Characterization}

The Fourier transform infrared sample studies were performed with a Thermo Scientific Nicolet iS10 analyzer (Thermo Fisher Scientific, Waltham, MA, USA), measuring in a range of $400-4000 \mathrm{~cm}^{-1} ; 32$ scans were obtained at a resolution of $4 \mathrm{~cm}^{-1}$. The textural properties of OP were determined using a BET parser (Micromeritics Tri star II plus). The 
determination of the isoelectric point of OP was carried out using the mass titration method described by Hernandez et al. [22].

\subsection{Pretreatment of Orange Peel}

The orange peel (Citrus sinensis) was collected, washed, and then dried at a temperature of $90{ }^{\circ} \mathrm{C}$ for $12 \mathrm{~h}$ and crushed until a particle size of $0.3 \mathrm{~mm}$ was obtained using sieving equipment (WACO TYLER RX-29, Mentor, OH, USA). Subsequently, treatments were carried out using methanol (MTOP), water (WTOP), and methanol-water (OPTmW); in each of them, $30 \%(\mathrm{wt} / \mathrm{v})$ was used between the orange peel and the solvent in each of the treatments, except for OPTmW, which was the combination of both treatments (first methanol and then water). After this was done, each sample was filtered and dried at $40^{\circ} \mathrm{C}$ in a forced convection oven (Shel Lab CE5F, Cornelius, OR, USA) for $24 \mathrm{~h}$. In MTOP, the shell-solvent mixture was left for $72 \mathrm{~h}$ at $200 \mathrm{rpm}$ at $30^{\circ} \mathrm{C}$ in a shaker (ZHICHENG ZHWY-200D, Huizhou, China), this was repeated seven times, while for WTOP it was carried out at $80^{\circ} \mathrm{C}$ for $1 \mathrm{~h}$ under vigorous stirring and was done until the filtrate no longer showed any color in the wastewater. In OPTmW it was a combination of the two previous pretreatments, the treatment with methanol was performed seven times, as was the treatment with water, with the same conditions mentioned above for each treatment. Parallel to the analysis of the adsorption capacity of orange peel, the obtaining of high added value compounds, such as polyphenols and flavonoids, was evaluated using different solvents that volatilize at different temperatures. Therefore, in the pretreatment of the adsorbent material, different temperatures were used to minimize solvent loss during the experimentation. The resulting OP from the three treatments was stored in an airtight bottle at room temperature until use.

\section{4. $\mathrm{Cr}$ (III) Adsorption at Equilibrium}

For the equilibrium studies of $\mathrm{Cr}$ (III) adsorption in WTOP, MTOP, and OPTmW, $0.5 \mathrm{~g}$ of bioadsorbent and $25 \mathrm{~mL}$ of $\mathrm{Cr}$ (III) solution were placed in a shaker (ZICHENG ZHWY-200D, Huizhou, China) with an orbital shaking of $200 \mathrm{rpm}$ at $30^{\circ} \mathrm{C}$ for $24 \mathrm{~h}$ of contact time. Varying concentrations were used, from 0 to $1000 \mathrm{ppm}$, at a pH of $0.91,1.78$ and 2.72 for $24 \mathrm{~h}$. The $\mathrm{pH}$ selection of the test solutions was carried out based on the results of the predominant species diagram, obtained by simulation using the Hydra Medusa, San Jose, CA, USA $)^{\circledR}$ program. During the development of the experiments, the $\mathrm{pH}$ of the solutions was monitored, and was kept stable by adding $0.05 \mathrm{M} \mathrm{HCl}$.

After this time, a sample aliquot was taken and centrifuged (HERMLE Z383K, Gosheim, Germany) at $4000 \mathrm{rpm}$ for $10 \mathrm{~min}$, subsequently, the absorbance was measured in the UVVis spectrum (Jenway 6705, Staffordshire, UK) [22,23]. All experiments were carried out in triplicate and the data were reported as average values of the replications. The adsorption capacity (q) of Cr (III) was determined using Equation (1) [24]:

$$
\mathrm{q}_{\mathrm{e}}=\frac{\left(\mathrm{C}_{0}-\mathrm{C}\right) \mathrm{V}}{\mathrm{m}}
$$

where $\mathrm{C}_{0}$ and $\mathrm{C}$ correspond to the initial and equilibrium concentration $\left(\mathrm{mg} \mathrm{L}^{-1}\right)$, respectively, $\mathrm{V}$ is the volume of the solution (L) and $\mathrm{m}$ is the mass of the adsorbent (g). The most-used non-linear adsorption isotherm models are shown in Table 1. SigmaPlot $12^{\circledR}$ (Systat Software, San Jose, CA, USA) was used to obtain the parameters of each of the models. 
Table 1. Non-linear adsorption isotherm models [23].

\begin{tabular}{cc}
\hline Model & Equation \\
\hline SIPS & $\mathrm{q}_{\mathrm{e}}=\frac{\mathrm{q}_{\mathrm{m}}\left(\mathrm{K}_{\mathrm{s}} \mathrm{C}_{\mathrm{e}}\right)^{\mathrm{n}_{\mathrm{s}}}}{1+\left(\mathrm{K}_{\mathrm{s}} \mathrm{C}^{\mathrm{n}_{\mathrm{s}}}\right.}$ \\
Redlich-Peterson (RP) & $\mathrm{q}_{\mathrm{e}}=\frac{\mathrm{K}_{\mathrm{R}} \mathrm{C}_{\mathrm{e}}}{1+\mathrm{a}_{\mathrm{R}} \mathrm{C}_{\mathrm{e}}^{\beta}}$ \\
Langmuir & $\mathrm{q}_{\mathrm{e}}=\frac{\mathrm{q}_{\mathrm{m}} \mathrm{K}_{\mathrm{L}} \mathrm{C}_{\mathrm{e}}}{1+\mathrm{K}_{\mathrm{L}} \mathrm{C}_{\mathrm{e}}}$ \\
Temkin & $\mathrm{q}_{\mathrm{e}}=\mathrm{A}+\mathrm{Bln}\left(\mathrm{C}_{\mathrm{e}}\right)$ \\
Freundlich & $\mathrm{q}_{\mathrm{e}}=\mathrm{K}_{\mathrm{F}} \mathrm{C}_{\mathrm{e}}^{\frac{1}{\mathrm{n}}}$ \\
Dubinin-Radushkevich (DR) & $\mathrm{q}_{\mathrm{e}}=\mathrm{q}_{\mathrm{m}} \exp \left(-\mathrm{k}_{\mathrm{DR}} \varepsilon^{2}\right)$ \\
\hline
\end{tabular}

The DR isotherm is generally applied to express the adsorption mechanism with a Gaussian energy distribution on a heterogeneous surface. The mean energy of sorption, E, is calculated using Equation (2) [10,23]:

$$
\mathrm{E}=\frac{1}{\sqrt{2 \mathrm{k}_{\mathrm{DR}}}}
$$

The magnitude of $\mathrm{E}$ is useful for estimating the type of sorption reaction [10]. The Gibbs free energy $(\Delta G)$, which allows knowing the spontaneity of the adsorption process, was calculated using Equation (3); it should be noted that, in the present study, the only molecular weight taken into account was that of $\mathrm{Cr}$ (III), discarding the one of the water, since the dimensional analysis $\mathrm{K}_{\mathrm{L}}$ is in terms of $\mathrm{L} / \mathrm{mg}$ of $\mathrm{Cr}$ (III) [24,25]:

$$
\Delta \mathrm{G}=-\mathrm{RT} \ln \left(55.5 \mathrm{~K}_{\mathrm{L}}\right)
$$

where $\mathrm{K}_{\mathrm{L}}$ is the Langmuir model constant $\left(\mathrm{L} \mathrm{mol}^{-1}\right)$, $\mathrm{R}$ is the ideal gas constant $\left(\mathrm{kJ} \mathrm{mol}^{-1} \mathrm{~K}^{-1}\right)$, and $\mathrm{T}$ is the absolute temperature $(\mathrm{K})$. The separation factor, $\mathrm{R}_{\mathrm{L}}$, which allowed predicting the affinity between adsorbent and adsorbate, was calculated using Equation (4) [24]:

$$
\mathrm{R}_{\mathrm{L}}=\frac{1}{1+\mathrm{K}_{\mathrm{L}} \mathrm{C}_{0}}
$$

From the proposed models, the one that fits the best needs to be chosen; for this, two different criteria were used: the first was the deterministic coefficient $\left(R^{2}\right)$, which must have a value close to 1 to consider a possible adjustment, and the second criterion is the normalized coefficient of determination, $\Delta q$, which was determined with the help of Equation (5) [22,26]: The choice of the model was made using the deterministic coefficient and the normalized standard deviation as selection criteria. The data processing was carried out with the Sigmaplot $12^{\circledR}$ program (Systat Software, San Jose, CA, USA).

$$
\Delta q=\sqrt{\frac{\left(\frac{q_{\exp }-q_{c a l}}{q_{\exp }}\right)^{2}}{N-1}} \times 100
$$

where $\mathrm{N}$ is the number of data points, $\mathrm{q}_{\text {exp }}$ and $\mathrm{q}\left(\mathrm{mg} \mathrm{g}^{-1}\right)$ are the values of the experimental adsorption capacity and that calculated using the model, respectively. Another parameter that was determined with the help of Equation (6) was the removal percentage, $\% R_{C r},[22,25]:$

$$
\% R_{C r}=\frac{\left(C_{0}-C\right)}{C_{0}} \times 100
$$

\subsection{Cr (III) Batch Adsorption Kinetics}

The removal kinetics of $\mathrm{Cr}$ (III) ions were carried out in batches to determine the evolution of $\mathrm{Cr}$ (III) adsorption in the biomaterial. The mass of the OP was varied with different 
treatments, from 0.1 to $0.5 \mathrm{~g}$ with $25 \mathrm{~mL}$ of $\mathrm{Cr}$ (III) solution at $500 \mathrm{ppm}$ at $\mathrm{pH} 0.91,1.78$, and 2.72. The closed containers were placed in a shaker (ZICHENG ZHWY-200D, Huizhou, China) at a speed of $200 \mathrm{rpm}$ and at $30^{\circ} \mathrm{C}$. Aliquots were taken every $1.5 \mathrm{~h}$ to separate the bioadsorbent by centrifugation (HERMLE Z383K, Gosheim, Germany) at $4000 \mathrm{rpm}$ and the supernatant was analyzed using UV-Vis spectroscopy (Jenway, Staffordshire, UK) at a wavelength of $425 \mathrm{~nm}$ to know the concentrations of the different ions present in the solution [27]. Table 2 shows the different kinetic models of $\mathrm{Cr}$ (III) adsorption.

Table 2. Kinetic models of adsorption [22,24].

\begin{tabular}{cc}
\hline Model & Equation \\
\hline Pseudo first order (PFO) & $\mathrm{q}=\mathrm{q}_{\max }\left[1-\exp \left(-\mathrm{k}_{1} \mathrm{t}\right)\right]$ \\
Pseudo second order (PSO) & $\mathrm{q}=\frac{\mathrm{t}}{\frac{1}{\mathrm{k}_{2} \mathrm{q}_{\max }}+\frac{\mathrm{t}}{\mathrm{q}_{\max }}}$ \\
Elovich & $\mathrm{q}=\frac{1}{\beta} \ln (\alpha \beta)+\frac{1}{\beta} \ln t$ \\
Intraparticle diffusion (ID) & $\mathrm{q}=\mathrm{k}_{\mathrm{id}} \mathrm{t}^{0.5}$ \\
External diffusion (ED) & $\mathrm{q}=\frac{\mathrm{C}_{0} \mathrm{~V}}{\mathrm{~m}}\left[1-\exp \left(-\mathrm{k}_{\exp } \mathrm{t}\right)\right]$ \\
\hline
\end{tabular}

\subsection{Desorption Study of $\mathrm{Cr}$ (III) Present in OP}

The reversibility of $\mathrm{Cr}$ (III) adsorption in OP was assessed with equilibrium $\mathrm{Cr}$ (III) removal experiments. The kinetic experiment described in Section 2.5 produced OP loaded with $\mathrm{Cr}$ (III), which was put into contact with a $25 \mathrm{~mL} 0.5 \mathrm{M} \mathrm{NaOH}$ solution for $24 \mathrm{~h}$. The amount of $\mathrm{Cr}$ (III) that remained adsorbed on OP was calculated by mass balance using Equation (7) [12,22]:

$$
\mathrm{q}_{\mathrm{d}}=\mathrm{q}_{0}-\frac{\mathrm{V}}{\mathrm{m}} \mathrm{C}
$$

where $\mathrm{q}_{0}$ is the amount of $\mathrm{Cr}(\mathrm{III})$ initially adsorbed $(\mathrm{mg} / \mathrm{g})$. $\mathrm{q}_{\mathrm{d}}$ is the amount of chromium that remained adsorbed in OP $(\mathrm{mg} / \mathrm{g}), \mathrm{C}$ is the $\mathrm{Cr}$ (III) concentration in the solution $(\mathrm{mg} / \mathrm{L})$, $\mathrm{V}$ is the $\mathrm{NaOH}$ solution volume (L) and $\mathrm{m}$ is OP mass (g). The percentage of $\mathrm{Cr}$ (III) removal was determined using Equation (8):

$$
\% \text { Des }=\frac{\left(\mathrm{q}_{0}-\mathrm{q}_{\mathrm{d}}\right)}{\mathrm{q}_{0}} \times 100
$$

where \% Des is the percentage of $\mathrm{Cr}$ (III) removed from the adsorbant, $\mathrm{q}_{0}$ is the amount of $\mathrm{Cr}$ (III) adsorbed by the adsorbant and $\mathrm{q}_{\mathrm{d}}$ is the amount of $\mathrm{Cr}$ (III) removed from the solution [22].

\subsection{Determination of OP Isoelectric Point}

The determination of the OP isoelectric point was performed using the mass titration method, using a Thermo Scientific (Orion 4 Star, Waltham, MA, USA) pH meter. The process started by suspending $50 \mathrm{mg}$ of sample in water at room temperature for $24 \mathrm{~h}$ until $\mathrm{pH}$ reached equilibrium. Then, the $\mathrm{pH}$ of the suspension around the solid was measured. After that, another $20 \mathrm{mg}$ of sample was added to the suspension, and it was kept at rest for $24 \mathrm{~h}$ so that the suspension reached equilibrium again. The whole process was repeated until the $\mathrm{pH}$ of the suspension remained constant regardless of the amount of added solids, this being the value of $\mathrm{pH}$, the point of zero charge for WOPT, MTOP, and OPTmA [22].

\section{Results}

\section{1. $\mathrm{Cr}$ (III) Adsorption Isotherms}

Figure $\mathrm{S} 1$ shows the experimental data obtained from the $\mathrm{Cr}$ (III) removal process at equilibrium with different treatments applied to OP; additionally, the adjustments obtained with the different models can be observed. Table 3 shows the parameters of each of the adsorption isotherms. The reported data are the average values of the replications that 
were carried out, in all cases, the standard deviation values were less than $5.0 \%$, and it can be seen that the best adjustment, regardless of the $\mathrm{pH}$ and treatment used in the OP, is that obtained using the Freundlich model. This indicates that the surface of the adsorbent presents heterogeneous active sites [28,29], the value of $n$ for WTOP was less than 1 (indicating that the adsorption process of $\mathrm{Cr}$ (III) in the bioadsorbent was chemical regardless of $\mathrm{pH}$ ), while for MTOP and OPTmW the value of $n$ was greater than 1 , this implied that the ion removal process is physical [24,30-32].

Table 3. Parameters of isotherm models at different $\mathrm{pH}$.

\begin{tabular}{|c|c|c|c|c|c|c|c|c|c|c|}
\hline \multirow{2}{*}{ Model } & \multirow{2}{*}{ Parameter } & \multicolumn{3}{|c|}{ WTOP } & \multicolumn{3}{|c|}{ MTOP } & \multicolumn{3}{|c|}{ OPTmW } \\
\hline & & 0.91 & 1.78 & 2.72 & 0.91 & 1.78 & 2.72 & 0.91 & 1.78 & 2.72 \\
\hline \multirow{4}{*}{ Freundlich } & KF & 0.0340 & 0.0318 & 0.0265 & 0.1551 & 0.1874 & 0.0726 & 0.0309 & 0.0204 & 0.1328 \\
\hline & $\mathrm{n}$ & 0.9835 & 0.9504 & 0.9207 & 1.4019 & 1.3572 & 1.0936 & 1.1246 & 0.9192 & 1.3047 \\
\hline & $\mathrm{R} 2$ & 0.9897 & 0.9974 & 0.9990 & 0.9843 & 0.9909 & 0.9800 & 0.9973 & 0.9694 & 0.9911 \\
\hline & $\Delta \mathrm{q}, \%$ & 0.4123 & 0.3465 & 0.5436 & 1.6518 & 1.7081 & 0.7291 & 0.7770 & 2.1495 & 1.5222 \\
\hline \multirow{5}{*}{ SIPS } & $\mathrm{KS}$ & 0.0021 & 0.0026 & 0.0021 & 0.0022 & 0.0028 & 0.0024 & 0.0008 & 0.0020 & 0.0009 \\
\hline & $\mathrm{qm}$ & 39.5687 & 45.9814 & 48.9957 & 26.0913 & 30.0010 & 39.0051 & 32.5885 & 26.3521 & 55.1599 \\
\hline & $\mathrm{nS}$ & 2.5231 & 2.5680 & 2.5339 & 1.6252 & 2.0878 & 2.7234 & 1.2414 & 1.9425 & 1.1245 \\
\hline & $\mathrm{R} 2$ & 0.9809 & 0.9703 & 0.9558 & 0.9974 & 0.9864 & 0.9684 & 0.9995 & 0.9119 & 0.9935 \\
\hline & $\Delta \mathrm{q}, \%$ & 1.7376 & 0.7235 & 0.3352 & 11.7912 & 1.0686 & 0.0803 & 58.4605 & 1.7788 & 51.6805 \\
\hline \multirow{5}{*}{$\mathrm{RP}$} & KR & 10.1023 & 2.2159 & 1.7722 & 0.0374 & 0.0495 & 0.0477 & 0.0175 & 46.9522 & 0.0404 \\
\hline & $\mathrm{aR}$ & 264.3194 & 48.2727 & 36.6792 & 0.0008 & 0.0009 & 0.0002 & 0.0002 & 0.1265 & 0.0005 \\
\hline & $\beta$ & $6.17 \times 10^{-18}$ & $1.19 \times 10^{-17}$ & $2.35 \times 10^{-18}$ & 1.0000 & 0.9581 & 1.0000 & 1.0000 & $2.96 \times 10^{-18}$ & 1.0000 \\
\hline & $\mathrm{R} 2$ & 0.9896 & 0.9965 & 0.9968 & 0.9915 & 0.9947 & 0.9820 & 0.9985 & 0.9693 & 0.9933 \\
\hline & $\Delta \mathrm{q}, \%$ & 71.5062 & 2.9880 & 10.9911 & 13.1963 & 13.8905 & 12.7091 & 113.5888 & 26.9331 & 9.7678 \\
\hline
\end{tabular}

The use of OP for the adsorption of $\mathrm{Cr}$ (III) has already been analyzed; however, there is no consensus regarding the adsorption model since the adjustment of the experimental data varies considerably, as well as in the different treatments that may be presented. Lugo-Lugo et al. [18], using OP treated with formaldehyde, obtained a better fit with the Langmuir model and an adsorption capacity of $9.43 \mathrm{mg} / \mathrm{g}$. For their part, Feng et al. [19] obtained an adsorption capacity of $72.73 \mathrm{mg} / \mathrm{g}$ with the same model. Additionally, other authors used different adsorbents, such as yucca [10], foxtail [7], Chlorella sorokiniana [33], Hylocomium splendens [15], Spirogyra spp. [34], and Sargassum filipendula [35], obtaining adsorption capacities of 41.6, 11.7, 56.68, 25, 30.21, and $33.02 \mathrm{mg} / \mathrm{g}$, respectively. Likewise, in the adsorption of $\mathrm{Cr}$ (III) with adsorbents, such as Hydrotalcites [28], Nannochloris microalgae [29], lichens [32], and carrot residues [30], adsorption capacities were reached at equilibrium of 17.0, 34.7, 52.1 and $45.09 \mathrm{mg} / \mathrm{g}$ respectively, adjusting with the Freundlich model. The adsorption capacity achieved with OP treated in the present study is within the adsorption range $(9.43$ and $72.73 \mathrm{mg} / \mathrm{g}$ ) reported by other authors, who used hexane, acetone, and formaldehyde in the pretreatment of OP. The results obtained suggest that the three treatments applied (water, methanol and methanol-water) to the orange peel at the three $\mathrm{pH}$ levels studied $(0.91,1.78$ and 2.72$)$ are within the range of the adsorption capacity reported in the literature [26]. It should be noted that based on the results of the simulation of the predominance of species, where it was observed that at a $\mathrm{pH}$ greater than 3.0 the $\mathrm{Cr}$ (III) solution precipitates into $\mathrm{Cr}_{2} \mathrm{O}$, and for solutions at a $\mathrm{pH}$ greater than 5.0 the species diagram shows that, in addition to $\mathrm{Cr}$ (III), the solution presents species such as $\mathrm{CrOH}^{2+}, \mathrm{Cr}(\mathrm{OH})^{4+}, \mathrm{Cr}(\mathrm{OH})^{5+}{ }_{4}$; in addition to the above, and taking into consideration that, in leather tanning, the $\mathrm{pH}$ values used with chromium salts are around 3.5 [31], it was decided to use a $\mathrm{pH}$ lower than 3.0 to avoid the precipitation of the $\mathrm{Cr}$ salt and the presence of other species.

Table 4 shows the $\Delta \mathrm{G}$ values obtained in the adsorption process of all the treatments at $30^{\circ} \mathrm{C}$. 
Table 4. $\Delta \mathrm{G}$ adsorption of $\mathrm{Cr}$ (III) with OP.

\begin{tabular}{cccc}
\hline & \multicolumn{3}{c}{$\mathbf{G}, \mathbf{k J} / \mathbf{m o l}$} \\
\hline $\mathrm{pH}$ & 0.91 & 1.78 & 2.72 \\
WTOP & 22.49 & 23.24 & 22.85 \\
MTOP & 23.58 & 23.31 & 23.02 \\
OPTmA & 22.68 & 22.18 & 23.38 \\
\hline
\end{tabular}

\subsection{Kinetics of Removal of $\mathrm{Cr}$ (III) Ions Using $\mathrm{OP}$}

Figure 1 shows the removal of $\mathrm{Cr}$ (III) using WTOP, where it is observed that the adsorption capacity increases with respect to $\mathrm{pH}$ in such a way that there is $38.67,45.24$, and $53.15 \mathrm{mg} / \mathrm{g}$ at $\mathrm{pH} 0.91,1.78$, and 2.72, respectively. A decrease in adsorption could also be observed when increasing the amount of mass present in the $\mathrm{Cr}$ (III) solution, which suggests that, despite increasing the presence of available active sites, these are more dispersed on the surface of WTOP, which makes it difficult to capture $\mathrm{Cr}$ ions because they do not have the necessary force to remove the ion from the solution. In contrast, when the active sites are closer to the surface, they can generate a significant force that removes the $\mathrm{Cr}$ (III) ions more easily, as they may not have the same energy, it is necessary to have more than one active site to remove $\mathrm{Cr}$ from the solution. In Table S1, the values of each parameter of the different adsorption kinetic models are shown considering the criterion of the deterministic coefficient $\left(R^{2}\right)$ and the normalized standard deviation $(\Delta q)$. The best fit is provided by the Elovich model, and this model infers that the active sites of the bioadsorbent are heterogeneous and therefore exhibit different activation energies and cause a better adsorption, confirming what was observed in the variation of mass present in the $\mathrm{Cr}$ (III) solution where the removal of these ions is also affected by the environment of the solution. At a pH of 0.91 there is a removal percentage of $24.4 \%$ which increased as the $\mathrm{pH}$ increased (at 1.78 there is $59.3 \%$ removal) $67.2 \%$ being the maximum removal percentage at a $\mathrm{pH}$ of 2.72 .
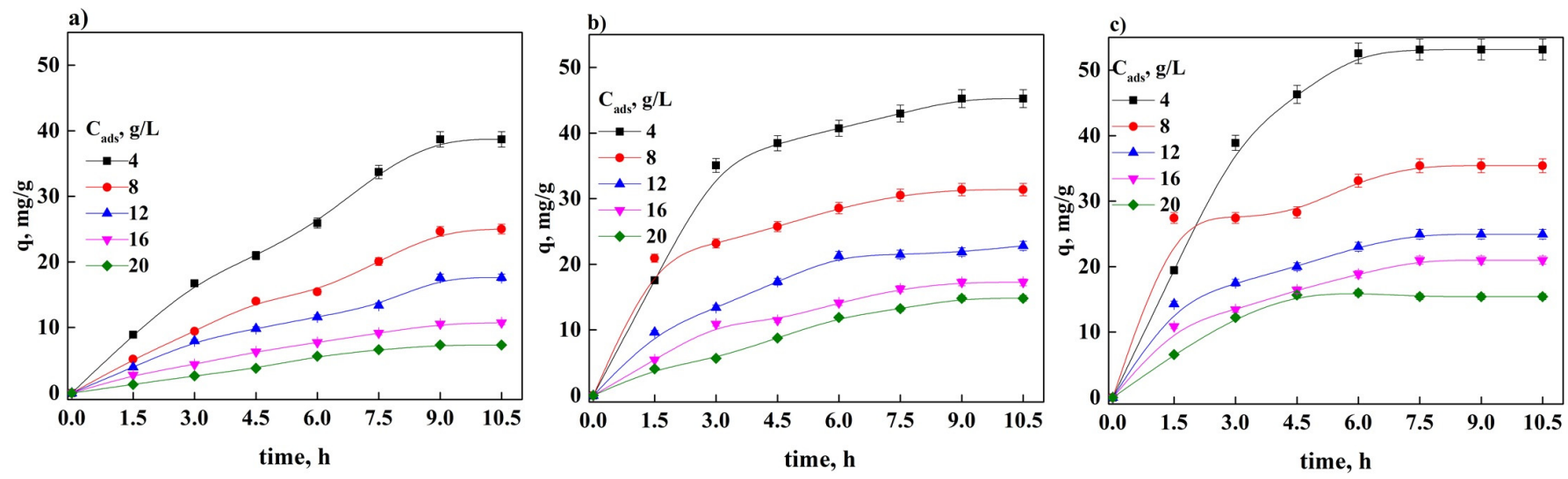

Figure 1. WTOP adsorption capacity at different pH: (a) 0.91, (b) 1.78 and (c) 2.72 .

Figure 2 shows the removal behavior of $\mathrm{Cr}$ (III) with MTOP, which is similar to that obtained with WTOP, where an increase in the adsorption capacity is found with the increase in $\mathrm{pH}$, obtaining values of 23.61, 29.97, and $43.17 \mathrm{mg} / \mathrm{g}$ at $\mathrm{pH} 0.91,1.78$, and 2.72 , respectively. This indicates that the applied treatment causes a significant change in the adsorption of $\mathrm{Cr}$ (III) since a decrease in the adsorption capacity of 38.44,33.75, and $22.53 \%$ is observed at $\mathrm{pH}$ of $0.91,1.78$, and 2.72 , respectively, in comparison with the values obtained with WTOP. Based on the parameters of the kinetic models obtained in Table S2, the best fit is also obtained with the Elovich model, which suggests that the nature of the active sites was not significantly altered by the treatment. The removal percentages of $\mathrm{Cr}$ (III) obtained with WTOP were $37.9 \%, 46.2 \%$, and $52.1 \%$ at a $\mathrm{pH}$ of $0.91,1.78$, and 2.72 respectively, when comparing these values with those obtained with the MTOP treatment, 
it is inferred that the treatment influences directly in the removal percentage because at $\mathrm{pH} 0.91,1.78$, and 2.72 there was a relationship of $1.55,1.28$, and 1.14 times more removal with WTOP compared to MTOP.
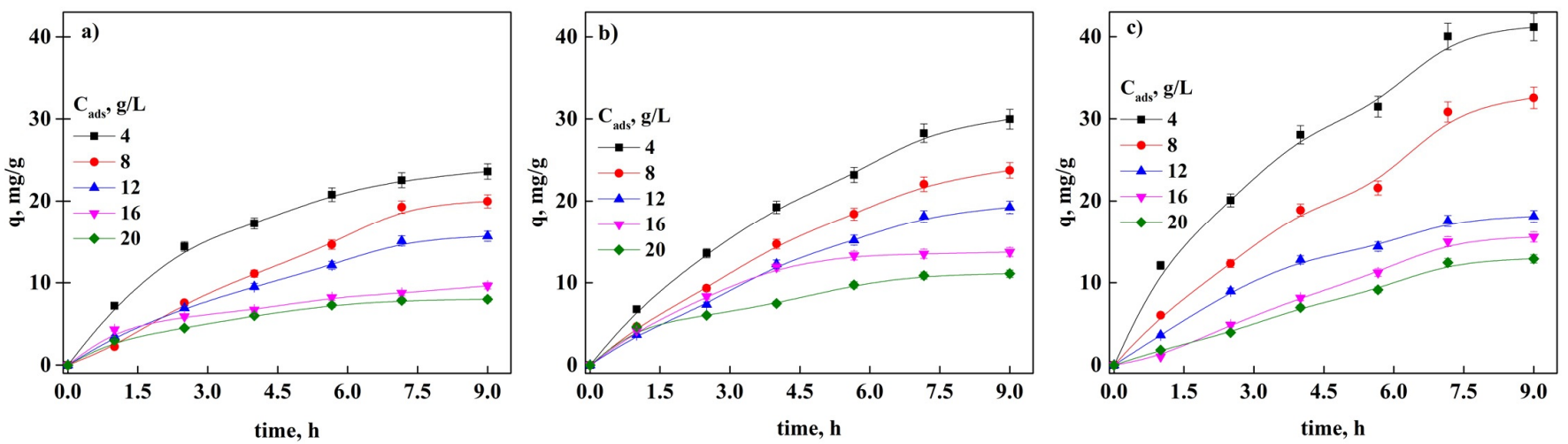

Figure 2. MTOP adsorption capacity at different pH: (a) 0.91, (b) 1.78 and (c) 2.72.

On the other hand, in the adsorption of $\mathrm{Cr}$ (III) with OPTmW (Figure 3) at pH 0.91, 1.78, and 2.72 , a removal capacity of $15.81,22.05$, and $30.34 \mathrm{mg} / \mathrm{g}$, respectively, was obtained, the behavior exhibited was similar to that of the other two treatments. Comparing the adsorption capacity values obtained between OPTmW and WTOP, decreases of 50.05, 51.23 and $42.91 \%$ are observed at $\mathrm{pH}$ of $0.91,1.78$ and 2.72 , respectively, which indicates that the combination of both treatments does not increase the $\mathrm{Cr}$ (III) adsorption capacity, and unlike what is expected, there is no synergistic effect. Table S3 shows the parameters of the different adsorption models obtained, where it can be seen that the best fit is presented with the Elovich model as with the two previous treatments. The removal percentages of $\mathrm{Cr}$ (III) with WTOP at $\mathrm{pH} 0.91,1.78$, and 2.72 were $0.84,1.4$, and 1.43 times higher compared to those obtained with OPTmW.
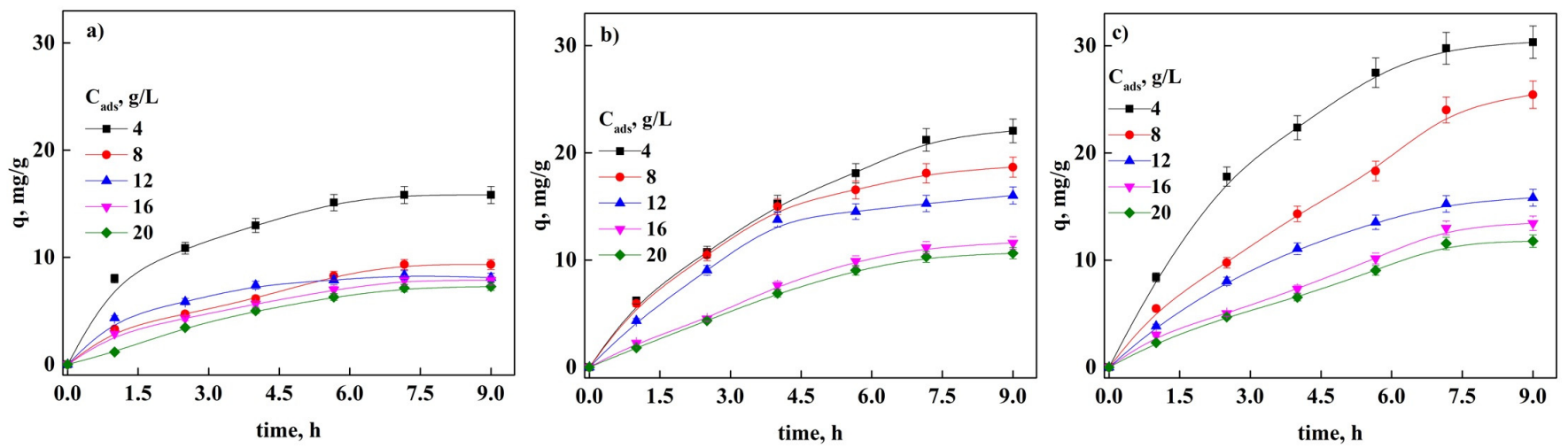

Figure 3. OPTmW adsorption capacity at different pH: (a) 0.91, (b) 1.78, and (c) 2.72 .

In Figures 1-3 it can be seen that the equilibrium stage for the adsorption of $\mathrm{Cr}$ (III) is achieved with different contact times. The time in which equilibrium is reached is affected by the type of pretreatment applied, in the case of WTOP, the time it reaches saturation on the surface decreases with increasing $\mathrm{pH}$, (at 0.91 the time is $9 \mathrm{~h}$, at 1.72 the time is $8 \mathrm{~h}$ and at 2.72 the time is $6 \mathrm{~h}$ ). In the case of WTOP and OPTmA, concerning $\mathrm{pH}$ with contact times of 7.0 and $7.5 \mathrm{~h}$, no apparent change is observed in the time in which saturation is reached. Likewise, in Figures 1-3, it can be observed that the amount of eliminated Cr (III) depends directly on the adsorbent concentration, decreasing with the increase in the OP mass for any treatment and/or $\mathrm{pH}$ of the solution, this effect is attributed to the clogging of the active sites in the adsorbent [22]. 
Several authors mention the effect of $\mathrm{pH}$ on the adsorption capacity and the percentage of removal of $\mathrm{Cr}$ (III) using OP [16-19], which agree with the results obtained, despite the differences in the operating conditions and treatments applied to the OP, among which were water washes, treatments with $\mathrm{HCl}, \mathrm{NaOH}(11.67 \mathrm{mg} / \mathrm{g})$ and with formaldehyde $(7.9 \mathrm{mg} / \mathrm{g})$, obtaining adsorption capacity values from $23.76 \mathrm{mg} / \mathrm{g}$ with $180 \mathrm{~h}$ at $\mathrm{pH}$ of 5 , up to $233.98 \mathrm{mg} / \mathrm{g}$ with $40 \mathrm{~h}$ of contact time. Among the conditions that differ in these treatments is the use of other adsorbents for the removal of $\mathrm{Cr}$ (III), different values of maximum adsorption capacity from $0.98 \mathrm{mg} / \mathrm{g}$ to $52 \mathrm{mg} / \mathrm{g}$ using hydrotalcites [28], gelatin [36], jackfruit peel [10], ground foxtail [7] and lichens [32]. Microorganisms such as Chlorella sorokiniana, Hylocomium splendens and algae such as Nannochloris, Spirogyra spp. and Sargassum filipendula have also been used, obtaining Cr (III) adsorption values of $23 \mathrm{mg} / \mathrm{g}$ [33], $4.14 \mathrm{mg} / \mathrm{g}$ [15], $37.7 \mathrm{mg} / \mathrm{g}$ [29], $30.21 \mathrm{mg} / \mathrm{g}$ [34] and $20.28 \mathrm{mg} / \mathrm{g}$ [35], respectively.

In the literature, it is also mentioned that the adsorption kinetics of $\mathrm{Cr}$ (III) conform to several models, using jackfruit treated with EDTA, $\mathrm{NaOH}$, and $\mathrm{HNO}_{3}$ at $\mathrm{pH}=4$ [10]; Citrus sinensis treated with water at $\mathrm{pH}=4$ [18]; rice husk at $\mathrm{pH}$ in the range of 5-6 [16]; carrot residues treated with $\mathrm{HCl}$ at $\mathrm{pH}$ in the range 2-5 [30]; Sargassum treated with formaldehyde at $\mathrm{pH}=2$ [35]; S. cerevisiae at $\mathrm{pH}=4.3$ [37], among the more reported are those of pseudo second order [15,17,18,29,30], pseudo first order [35], and Elovich [19], which is consistent with what was obtained in the present work. Similarly, it has been reported that the percentage of removal of $\mathrm{Cr}$ varies from $40 \%$ to $95 \%$ [10,18,19,30,35,38,39]; therefore, it is possible that WTOP is a biomaterial with optimal Cr (III) adsorption and removal capacity that allows considering this bioadsorbent as a candidate for use in the elimination of $\mathrm{Cr}$ (III) ions in aqueous solution.

\subsection{Limitations for External and Internal Mass Transfer}

From the data provided in Tables S1-S3, it was found that the model that best fits the experimental data of the kinetic process of $\mathrm{Cr}$ (III) removal is Elovich's; however, there are also other models that provided information on limitations due to internal and external mass transfer. As such, it was necessary to carry out more extensive analyses on these phenomena in the $\mathrm{Cr}$ (III) removal process (Table S4), for which the graphs shown in Figure 4 were constructed. It was observed that, for all samples and at any $\mathrm{pH}$, a straight line is constructed with the experimental data in the first $3.25 \mathrm{~h}$ of contact in the adsorption, except for WTOP at $\mathrm{pH}$ 0.91, where this event occurs at $4.5 \mathrm{~h}$; the presence of this straight line suggests that there is an external mass transfer.

This result indicates that it is important to establish whether there are internal mass transfer limitations to determine which phenomena could significantly influence the overall speed of the adsorption process. Figure S2 shows the behavior of q vs. $t^{0.5}$, based on the intraparticle diffusion model (Table 2); in this figure, three stages can be observed: external diffusion, internal diffusion, and equilibrium [22,26]. Defining each of the stages, it is also possible to determine the mass transfer rate constants in such a way that the process that dominates the removal of $\mathrm{Cr}$ (III) can be known. Table 5 shows the speed constants of the different treatments applied, using the $k_{1} / k_{2}>1$ criterion, which indicates that mass transfer by external diffusion dominates the global adsorption process, where $k_{1}$ represents external diffusion and $k_{2}$ internal diffusion [22,26].

The results obtained show that in the adsorption of Cr (III) in OPTmW the external diffusion dominates, which causes the $\mathrm{Cr}$ (III) ions to take time to arrive from the core of the solution to the surface of the adsorbent, and therefore, more energy is needed to capture the ions on the surface, and this causes the adsorption capacity to be lower compared to the other two treatments. In MTOP, there are internal diffusion limitations at a $\mathrm{pH}$ of 0.91 and 1.78 , but at a $\mathrm{pH}$ of 2.72 there are external mass transfer problems, which is why it has a lower adsorption capacity compared to WTOP at the same pH. Finally, in WTOP there are external mass transfer problems at $\mathrm{pH}<2.72$, which explains the fact that the maximum adsorption capacity is present at $\mathrm{pH}$ equal to 2.72 , due to the fact that less energy is required to remove the $\mathrm{Cr}$ (III) ions from the solution. 
a)
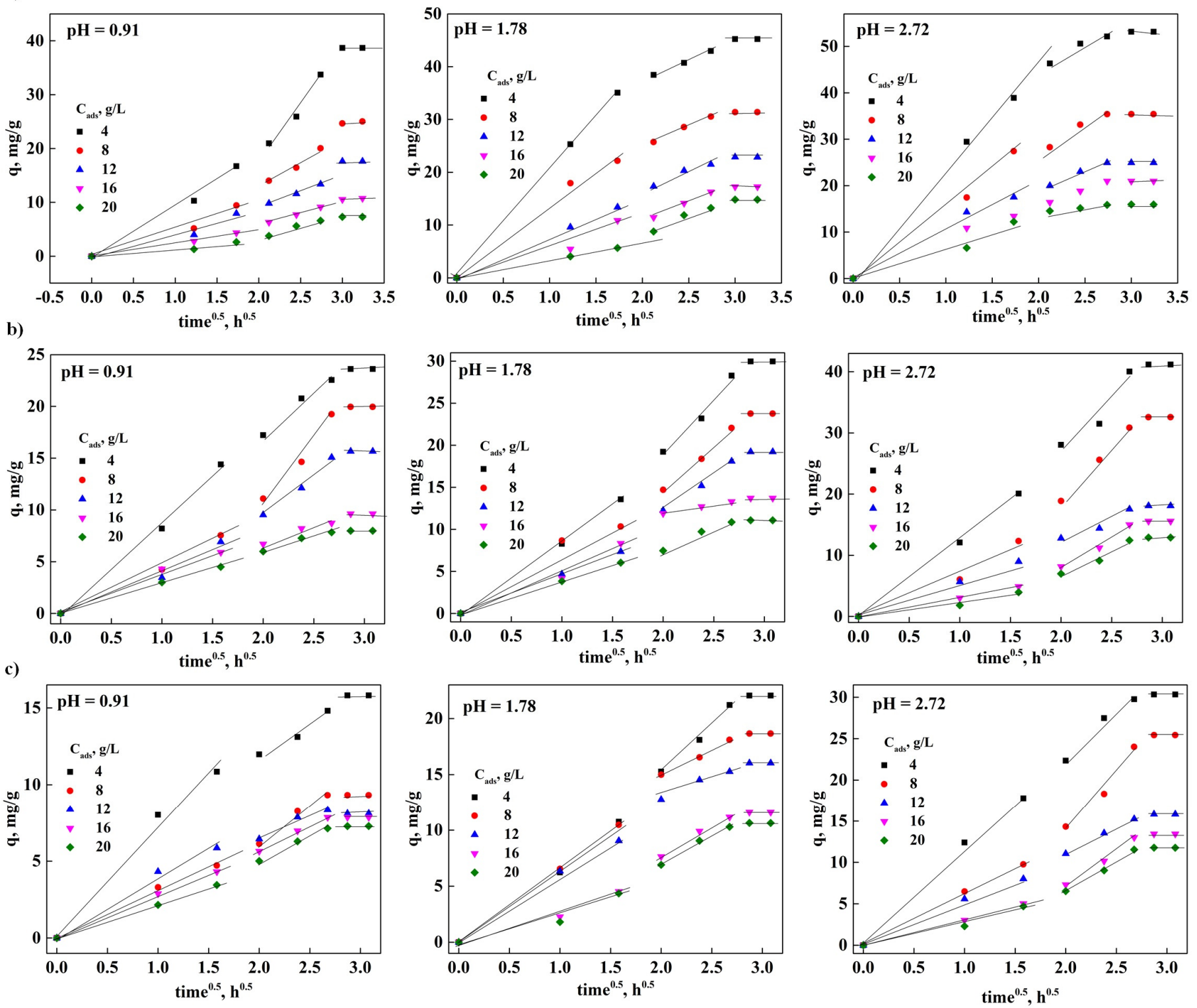

Figure 4. Analysis of external mass transport at different pH, (a) WTOP, (b) MTOP, and (c) OPTmA.

\subsection{Desorption of $\mathrm{Cr}$ (III) Loaded in OP}

The result of the desorption process (Figure 5) suggests that the removal rate of $\mathrm{Cr}$ (III) on the surface of OP depends on the $\mathrm{pH}$ and the treatment of the bioadsorbent, which suggests that a portion of the ions on the surface are easily removed, especially with $\mathrm{pH}$ less than 1, which has a desorption percentage greater than $50 \%$ for both MTOP $(51.8 \%)$ and WTOP (53.0\%). This causes an increase in the number of sites available for the reabsorption of the ions present in the solution, which agrees with what was reported in other studies [20,22]; however, with a $\mathrm{pH}$ greater than 1, there are removal percentages that remain practically constant for WTOP and MTOP. This result indicates that the process is reversible and provides an idea of the desorption capacity; however, it is necessary to carry out an extensive investigation that evaluates different operating conditions and with which the regeneration capacity of the treated orange peel can be optimized. For OPTmW, it was observed that the desorption of $\mathrm{Cr}$ (III) depends on the concentration of the present adsorbent $\left(C_{\text {ads }}\right)$, having a maximum removal percentage of $27 \%$, which indicates that a greater energy would be needed to try to remove the metal from the surface of the adsorbent, compared to that used with the other two treatments. Similar 
results in the $\mathrm{Cr}(\mathrm{VI})$ removal process have been reported using the same concentration of $\mathrm{NaOH}[10,22,40]$.

Table 5. Kinetic constants for external and internal diffusion processes.

\begin{tabular}{|c|c|c|c|c|c|c|c|c|c|}
\hline \multicolumn{4}{|c|}{ WTOP } & \multicolumn{3}{|c|}{ MTOP } & \multicolumn{3}{|c|}{ OPTmW } \\
\hline \multicolumn{10}{|c|}{$\mathrm{pH}=0.91$} \\
\hline $\begin{array}{l}\mathrm{C}_{\text {ads, }} \\
\mathrm{g} / \mathrm{L}\end{array}$ & $k_{1}, \underset{\mathrm{h}^{0.5}}{\mathrm{mg}} / \mathrm{g}$ & $k_{2}, \underset{\mathrm{h}^{0.5}}{\mathrm{mg}} / \mathrm{g}$ & $k_{1} / k_{2}$ & $k_{1}, \underset{\mathrm{h}^{0.5}}{\mathrm{mg}} / \mathrm{g}$ & $k_{2}, \underset{\mathrm{h}^{0.5}}{\mathrm{mg} / \mathrm{g}}$ & $k_{1} / k_{2}$ & $k_{1}, \underset{\mathrm{h}^{0.5}}{\mathrm{mg}} / \mathrm{g}$ & $k_{2}, \underset{\mathrm{h}^{0.5}}{\mathrm{mg}} / \mathrm{g}$ & $k_{1} / k_{2}$ \\
\hline 4 & 20.55 & 9.232 & 2.226 & 7.936 & 8.846 & 0.897 & 7.192 & 4.141 & 1.737 \\
\hline 8 & 9.709 & 5.312 & 1.828 & 4.622 & 11.94 & 0.387 & 4.761 & 3.073 & 1.549 \\
\hline 12 & 5.735 & 4.133 & 1.388 & 4.118 & 8.156 & 0.505 & 3.884 & 2.860 & 1.358 \\
\hline 16 & 4.584 & 2.427 & 1.891 & 3.057 & 3.898 & 0.784 & 3.289 & 2.772 & 1.187 \\
\hline 20 & 4.618 & 1.372 & 3.367 & 2.757 & 2.891 & 0.954 & 3.157 & 2.173 & 1.453 \\
\hline \multicolumn{10}{|c|}{$\mathrm{pH}=1.78$} \\
\hline 4 & 20.39 & 7.321 & 2.785 & 8.496 & 13.258 & 0.641 & 8.7282 & 6.627 & 1.317 \\
\hline 8 & 13.42 & 7.808 & 1.712 & 7.142 & 10.827 & 0.661 & 6.5951 & 5.769 & 1.143 \\
\hline 12 & 7.771 & 6.771 & 1.147 & 4.656 & 8.606 & 0.541 & 5.8969 & 5.357 & 1.101 \\
\hline 16 & 7.798 & 5.672 & 1.375 & 4.959 & 1.766 & 2.809 & 5.2646 & 2.681 & 1.964 \\
\hline 20 & 7.289 & 3.285 & 2.221 & 3.829 & 5.649 & 0.678 & 5.0513 & 2.484 & 2.034 \\
\hline \multicolumn{10}{|c|}{$\mathrm{pH}=2.72$} \\
\hline 4 & 9.545 & 22.98 & 0.415 & 17.33 & 12.52 & 1.384 & 11.5779 & 9.309 & 1.244 \\
\hline 8 & 11.62 & 15.31 & 0.759 & 17.72 & 7.292 & 2.431 & 13.4812 & 6.256 & 2.155 \\
\hline 12 & 8.034 & 10.63 & 0.755 & 6.906 & 5.096 & 1.355 & 5.5757 & 5.219 & 1.068 \\
\hline 16 & 7.391 & 8.126 & 0.909 & 10.03 & 3.061 & 3.277 & 7.4106 & 3.131 & 2.367 \\
\hline 20 & 2.091 & 6.497 & 0.322 & 7.957 & 2.303 & 3.456 & 6.3875 & 2.781 & 2.297 \\
\hline
\end{tabular}
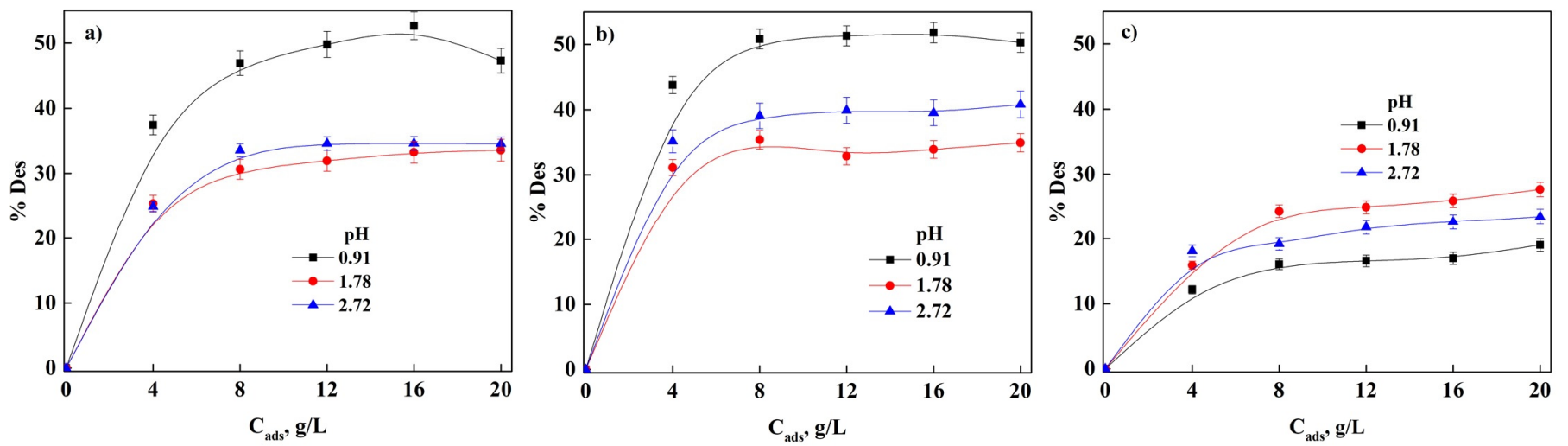

Figure 5. Cr (III) desorption at different pH and treatment: (a) WTOP, (b) MTOP and (c) OPTmW.

\subsection{Characterization of $O P$}

In Figure S3, the adsorption-desorption isotherm of WTOP is observed and in the box is a broad image of the hysteresis that is formed in the isotherm which is type IV (UIPAC classification), which indicates that it has a porous structure [41-44], with an area of $2.85 \mathrm{~m}^{2} / \mathrm{g}$, and an average pore size of $5.49 \mathrm{~nm}$; thus, the bioadsorbent is classified as a mesoporous material $(2-50 \mathrm{~nm})$. OP is a mesoporous adsorbent as it has been indicated in some works [42,43], depending on the pretreatment used in the biomaterial, a specific area between 1.19 and $10 \mathrm{~m}^{2} / \mathrm{g}[42,44]$ is obtained, which contributes favorably to the good adsorption capacity of OP.

The isoelectric points of the biadsorbents including untreated OP were determined as shown in Figure 6, obtaining values of 3.32, 4.10, 5.08, and 6.04 that correspond to OP, WTOP, OPTmW, and MTOP, respectively. Taking into consideration the obtained values, it is inferred that the adsorption of $\mathrm{Cr}$ (III) on the surface is not carried out by electrostatic forces because the $\mathrm{pH}$ of the solutions is less than 2.72 and the surface of the bioadsorbents is positively charged, which implies that an exchange of species, such as $\mathrm{OH}$ (in basic medium), can be carried out on the surface of the orange peel, although there is no electrostatic attraction, which depends directly on the characteristics of the bioadsorbent $[12,22,45,46]$. 
The orange peel has compounds with functional groups that can participate in the pollutant removal processes. Figure 7 shows the IR spectra of OP before being in contact with the Cr (III) solution, which is why the $\mathrm{pH}$ is not specified; the following peaks were observed: at $3295 \mathrm{~cm}^{-1}$ corresponds to the vibrations of the O-H group of cellulose, hemicellulose, lignin, pectin, or adsorbed water. The peak at $2928 \mathrm{~cm}^{-1}$ is attributed to the vibrations of the asymmetric and symmetric stretching of the $\mathrm{C}-\mathrm{H}$ groups in aliphatic acids and the peak at $2850 \mathrm{~cm}^{-1}$ is due to the symmetric vibrations of the $-\mathrm{CH}_{2}$ - group of aliphatic acids. The presence of free and esterified carboxylic groups are found with the peaks at 1736 and $1632 \mathrm{~cm}^{-1}$, respectively. The band at $1419 \mathrm{~cm}^{-1}$ can be attributed to the plane strain vibration of the methyl, methylene and methoxy groups in aliphatic and aromatic compounds. The symmetric stretching of -COO- is due to the peak at $1380 \mathrm{~cm}^{-1}$ and at $1330 \mathrm{~cm}^{-1}$ it corresponds to the stretching vibration of the C-O groups of carboxylic acids and alcohols. The peak at $1241 \mathrm{~cm}^{-1}$ is attributed to the vibrations of the COO-group. At $1008 \mathrm{~cm}^{-1}$ it is due to the stretching vibrations of the $\mathrm{C}-\mathrm{H}, \mathrm{C}-\mathrm{O}-\mathrm{H}$ or C-O-R groups of the alcohols and carboxylic acids [16-18,45-48]. The intensity of the peaks in the samples decreases in the following order: OP $>$ WTOP $>$ MTOP $>$ OPTmW, this means that there is less presence of the functional groups of the different compounds present in OP (cellulose, pectin, aliphatics, etc.).

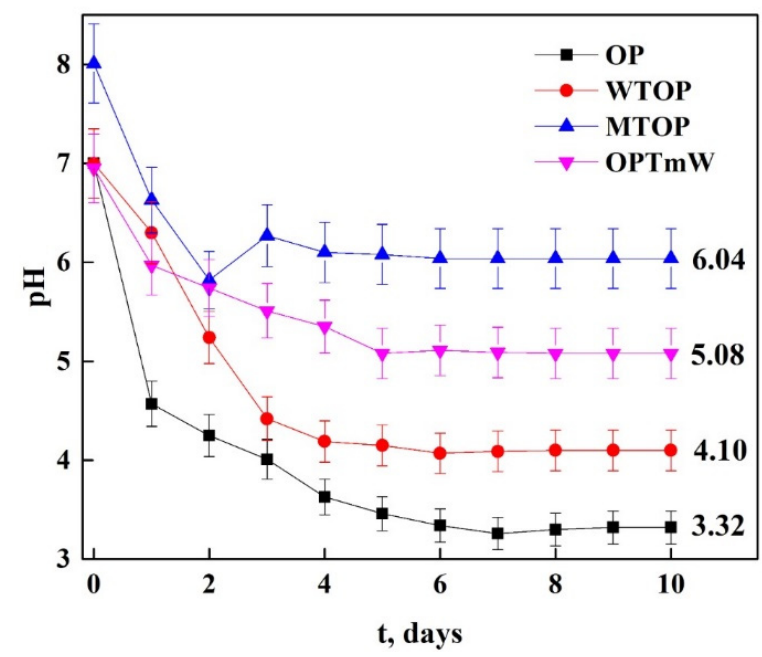

Figure 6. Isoelectric point of the different samples.

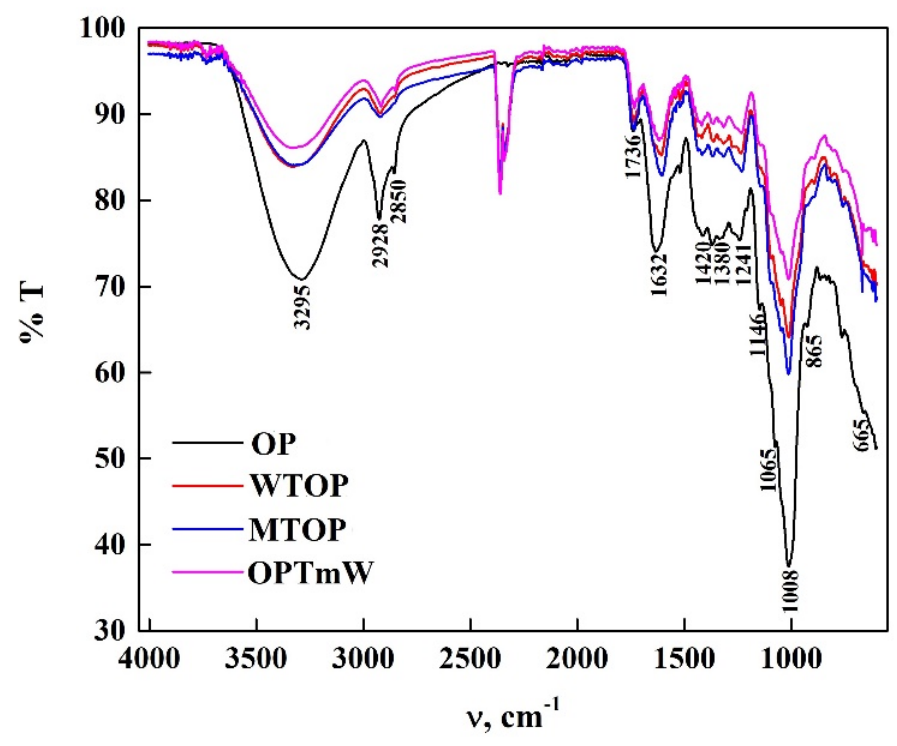

Figure 7. FTIR spectra of OP in different unused treatments. 
On the other hand, the FTIR spectra of the samples were taken after the Cr (III) adsorption process at different $\mathrm{pH}$ values, which are presented in Figure S4. It can be observed that the intensity of the functional groups present in the OP was significantly modified since the intensity decreased as the $\mathrm{pH}$ of the solution increased, or, in some cases, the peak disappeared, this is indicative of the participation of the functional groups in the capture of $\mathrm{Cr}$ ions.

In the case of WTOP, it is observed that the intensity of the peaks at 3290, 2896, 1721, $1630,1414,1367$, and $1008 \mathrm{~cm}^{-1}$ decreased, which indicates that there are several functional groups participating in the $\mathrm{Cr}$ adsorption process (III) in the orange peel; for example, the $\mathrm{OH}$ groups of cellulose, hemicellulose, pectin, as well as the $\mathrm{CH}, \mathrm{CH}_{2}$ groups of aliphatic compounds and carboxylic groups and esters. The peak at $1322 \mathrm{~cm}^{-1}$ did not present a significant change, which indicated that the functional group $\mathrm{COO}$ - has no participation in the removal of $\mathrm{Cr}$ (III), there are also bands that disappear in WTOP at pH 2.7, such as 1367, 865 and $665 \mathrm{~cm}^{-1}$ that are attributed to the C-O groups of carboxylic acids and alcohols.

With MTOP, a similar behavior to WTOP is observed, although the decrease in the intensity of the peaks is less than that of the shell treated with water; however, in the MTOP samples, it is observed that the following bands disappear: $1420,1147,863$, and $665 \mathrm{~cm}^{-1}$, which indicates that in addition to the previously mentioned functional groups, the $\mathrm{CH}_{2}$, $\mathrm{CH}_{3}$, and $\mathrm{OCH}_{3}$ groups belonging to the aliphatic compounds of the biomaterial also participate in the adsorption. This is probably because the functional groups $\mathrm{CH}_{2}, \mathrm{CH}_{3}$, and $\mathrm{OCH}_{3}$, present in the pretreated orange peel can be in various combinations, which particularly influences the properties of the material, including the structure and reactivity. This is reflected in the hydrophobic or hydrophilic character of the adsorbent material; additionally, the degree of dissociation of chromium in solution at different $\mathrm{pH}$ allows the electrostatic bonding of CR (III) and the functional groups of the shell to be established.

OPTmW presented a similar behavior compared with the other two treatments; however, the decrease in the intensity of the peaks was proportionally less compared to that obtained by the other two treatments, in the bands at 1420,1147, 863, and $665 \mathrm{~cm}^{-1}$. The peak at $1067 \mathrm{~cm}^{-1}$ attributed to the $\mathrm{C}-\mathrm{O}$ groups of the carboxylic acids and alcohols present in the orange peel, disappeared in this treatment. The participation of the different functional groups has been reported in several works $[3,9,16,18]$, where the interaction that exists between functional groups and $\mathrm{Cr}$ ions is mentioned. The results obtained at a $\mathrm{pH}$ of 2.7 suggest that the $\mathrm{Cr}$ adsorption process on the surface of the OP does not depend on electrostatic attraction, but on the presence of functional groups on the surface of the material, and that the higher the concentration of these groups, the better the removal of $\mathrm{Cr}$.

Based on all the results obtained, it can be assumed that OP can be used as a low-cost bioadsorbent, given its abundance, renewable nature, and the fact that it requires minimal processing for its use as an adsorbent, in addition to having a similar adsorption capacity to that of those adsorbents reported in the literature. Additionally, the use of OP as a bioadsorbent material would contribute to the protection of the environment by avoiding contamination of the soil, water, and air due to the presence of these easily fermentable residues in sanitary landfills.

\section{Conclusions}

The results obtained show that the best conditions for the removal of $\mathrm{Cr}$ (III) present in the aqueous solution are at the highest $\mathrm{pH}$, that is, 2.72, with WTOP being the best treatment with an adsorption capacity of $53.15 \mathrm{mg} / \mathrm{g}$. The best adjustment in the $\mathrm{Cr}$ (III) adsorption was presented with the Freundlich model, while in the kinetic process a better adjustment was had with the Elovich model. Both models mention that both the surface and the active sites have heterogeneous energy, which allows for better adsorption. On the other hand, values between 0 and 1 of the separation factor $\left(R_{L}\right)$ were determined, which indicates that the elimination of $\mathrm{Cr}$ (III) is favorable, in addition, with the D-R isotherm it was found that the process of capturing the ions carried out through the ion exchange mechanism with the surface and that the removal is spontaneous $(\Delta G<0)$. 
In the study of mass transfer in the adsorption of $\mathrm{Cr}$ (III), it was observed that in the case of WTOP at pH 2.72 the internal mass transfer dominates, while in the other tests there is influence of the external mass transfer, which causes it to have a lower adsorption capacity compared to WTOP. The desorption study showed that for the WTOP and MTOP cases there is a recovery percentage greater than $40 \%$, which implies that $\mathrm{Cr}$ (III) can be recovered to be reused in various industrial processes, such as in a tannery. The characterization of the bioadsorbents revealed that there is no presence of electrostatic forces that are involved in the removal process of the $\mathrm{Cr}$ ions, while the analysis of the surface by FTIR showed that the functional groups of OP are modified with the applied treatment. Furthermore, its presence significantly affects the adsorption process on the surface of the adsorbent, with WTOP being the one with the highest presence of these functional groups, which is why it has a better adsorption at a $\mathrm{pH}$ of 2.72. Based on the percentages of desorption obtained, it is considered necessary to analyze the removal of $\mathrm{Cr}$ (III) from the orange peel using different operating conditions to achieve high recovery of $\mathrm{Cr}$ (III) and thus be able to reuse both the tanning salts and the orange peel in adsorption processes, to improve the profitability and sustainability of this process.

The contribution of this project regarding sustainability lies in the fact that the use of orange peel, discarded from various processes in the food industry, is an alternative to avoid contamination of soils and the environment due to the disposal without treatment of these easily fermentable residues. Considering that this material has adsorption capacity within the range of other materials contemplated in the literature.

Supplementary Materials: The following are available online at https:/ / www.mdpi.com/article / 10.3390/app11146346/s1, Figure S1: Fitting the experimental data with the adsorption isotherms of WTOP, MTOP and OPTmA with different pH, (a) 0.91, (b) 1.78 and (c) 2.72; Figure S2: Analysis of internal mass transport at different pH. (a) WTOP, (b) MTOP and (c) OPTmW; Figure S3: FT-IR spectra of OP in the adsorption of Cr (III) with different treatments: (a) WTOP, (b) MTOP and (c) OPTmW; Figure S4: FT-IR spectra of OP in Cr (III) adsorption with different treatments: (a) WTOP, (b) MTOP and (c) OPTmW; Table S1: Kinetic data of the Cr (III) removal using WTOP; Table S2: Kinetic data of $\mathrm{Cr}$ (III) removal using MTOP; Table S3: Kinetic data of Cr (III) removal using OPTmW; Table S4: Linear regression of the fit of the data that is part of the external transport process.

Author Contributions: Conceptualization, L.P.-S. and J.A.H.; Formal analysis, J.A.H. and R.H.-S.; Investigation, L.P.-S. and J.A.H.; Methodology, A.A., M.S.-H. and A.T.; Writing-original draft, L.P.-S. and J.A.H.; Writing-review and editing, R.H.-S. All authors have read and agreed to the published version of the manuscript.

Funding: This research was funded by the Secretary for Research and Graduate Studies (project SIP 20160593) of the Instituto Politécnico Nacional (IPN).

Institutional Review Board Statement: Not Applicable.

Informed Consent Statement: Not Applicable.

Data Availability Statement: Not Applicable.

Acknowledgments: The researchers want to thank UPIIG-IPN and UAM-Iztapalapa for the infrastructure provided to carry out this research.

Conflicts of Interest: The authors declare no conflict of interest.

\section{References}

1. Bhatnagar, A.; Sillanpää, M.; Witek-Krowiak, A. Agricultural waste peels as versatile biomass for water purification-A review. Chem. Eng. J. 2015, 270, 240-271. [CrossRef]

2. Anastopoulos, I.; Bhatnagar, A.; Hameed, B.H.; Ok, Y.S.; Omirou, M. A review on waste-derived adsorbents from sugar industry for pollutant removal in water and wastewater. J. Mol. Liq. 2017, 240, 179-188. [CrossRef]

3. Varghese, A.G.; Paul, S.A.; Latha, M.S. Remediation of heavy metals and dyes from wastewater using cellulose-based adsorbents. Environ. Chem. Lett. 2019, 17, 867-877. [CrossRef] 
4. $\quad$ Elabbas, S.; Leclerc, J.P.; Mandi, L.; Berrekhis, F.; Pons, M.N.; Ouazzani, N. Removal of Cr(III) from chrome tanning wastewater by adsorption using two natural carbonaceous materials: Eggshell and powdered marble. J. Environ. Manag. 2016, 166, 589-595. [CrossRef]

5. Femina Carolin, C.; Kumar, P.S.; Saravanan, A.; Joshiba, G.J.; Naushad, M. Efficient techniques for the removal of toxic heavy metals from aquatic environment: A review. J. Environ. Chem. Eng. 2017, 5, 2782-2799. [CrossRef]

6. Jacob, J.J.; Varalakshmi, R.; Gargi, S.; Jayasri, M.A.; Suthindhiran, K. Removal of Cr (III) and Ni (II) from tannery effluent using calcium carbonate coated bacterial magnetosomes. Clean Water 2018, 1, 1-10. [CrossRef]

7. Peng, S.H.; Wang, R.; Yang, L.Z.; He, L.; He, X.; Liu, X. Biosorption of copper, zinc, cadmium and chromium ions from aqueous solution by natural foxtail millet shell. Ecotoxicol. Environ. Saf. 2018, 165, 61-69. [CrossRef]

8. Arim, A.L.; Cecílio, D.F.M.; Quina, M.J.; Gando-Ferreira, L.M. Development and Characterization of Pine Bark with Enhanced Capacity for Uptaking Cr(III) from Aqueous Solutions. Can. J. Chem. Eng. 2018, 96, 855-864. [CrossRef]

9. Arim, A.L.; Guzzo, G.; Quina, M.J.; Gando-Ferreira, L.M. Single and binary sorption of $\mathrm{Cr}(\mathrm{III})$ and Ni(II) onto modified pine bark. Environ. Sci. Pollut. Res. 2018, 28, 28039-28049. [CrossRef]

10. Ranasinghe, S.H.; Navaratne, A.N.; Priyantha, N. Enhancement of adsorption characteristics of Cr(III) and Ni(II) by surface modification of jackfruit peel biosorbent. J. Environ. Chem. Eng. 2018, 6, 5670-5682. [CrossRef]

11. Rangabhashiyam, S.; Amith, K.D.; Selvaraju, N.; Mohan, B.R.; Muhammed Anzil, P.K.; Ushakumary, E.R. Hydrous Cerium Oxide Nanoparticles Impregnated Enteromorpha sp. for the Removal of Hexavalent Chromium from Aqueous Solutions. J. Environ. Eng. 2015, 142, C4015016. [CrossRef]

12. Flores-Cano, J.V.; Aragón-Pin, A.; Leyva-Ramos, R.; Salazar-Rabago, J.J.; Carrasco-Marin, F.; Leyva-Ramos, S. Adsorption mechanism of chromium(III) from water solution on bone char: Effect of operating conditions. Adsorption 2016, 22, 297-308. [CrossRef]

13. Umar, F.; Janusz, A.; Kozinski-Misbahul, A.K.; Makshoof, A. Biosorption of heavy metal ions wheat based biosorbents-A review of the recent literature. Biores. Technol. 2010, 101, 5043-5053. [CrossRef]

14. Dai, Y.; Sun, Q.; Wang, W.; Lu, L.; Liu, M.; Li, J.; Yang, S.; Sun, Y.; Zhang, K.; Xu, J.; et al. Utilizations of agricultural waste as adsorbent for the removal of contaminants: A review. Chemosphere 2018, 211, 235-253. [CrossRef]

15. Sari, A.; Mendil, D.; Tuzen, M.; Soylak, M. Biosorption of Cd (II) and Cr (III) from aqueous solution by moss (Hylocomium splendens) biomass: Equilibrium, kinetic and thermodynamic studies. Chem. Eng. J. 2009, 144, 1-9. [CrossRef]

16. Dias, D.; Lapa, N.; Bernardo, M.; Ribeiro, W.; Matos, I.; Fonseca, I.; Pinto, F. Cr(III) removal from synthetic and industrial wastewaters by using cogasification chars of rice waste streams. Bioresour. Technol. 2018, 266, 139-150. [CrossRef]

17. Singh, K.K.; Hasan, S.H.; Talat, M.; Singh, V.K.; Gangwar, S.K. Removal of Cr (VI) from aqueous solutions using wheat bran. Chem. Eng. J. 2009, 151, 113-121. [CrossRef]

18. Lugo-Lugo, V.; Barrera-Díaz, C.; Ureña-Núñez, F.; Bilyeu, B.; Linares-Hernández, I. Biosorption of Cr (III) and Fe (III) in single and binary systems onto pretreated orange peel. J. Environ. Manag. 2012, 112, 120-127. [CrossRef]

19. Feng, N.; Guo, X.; Liang, S.; Zhu, Y.; Liu, J. Biosorption of heavy metals from aqueous solutions by chemically modified orange peel. J. Hazard. Mater. 2011, 185, 49-54. [CrossRef]

20. Pérez-Marín, A.B.; Aguilar, M.I.; Meseguer, V.F.; Ortuño, J.F.; Sáez, J.; Lloréns, M. Biosorption of chromium (III) by orange (Citrus cinensis) waste: Batch and continuous studies. Chem. Eng. J. 2009, 155, 199-206. [CrossRef]

21. Chen, H.; Dou, J.; Xu, H. Removal of $\mathrm{Cr}(\mathrm{VI})$ ions by sewage sludge aqueous compost biomass from solutions: $\mathrm{Reduction}$ to $\mathrm{Cr}(\mathrm{III})$ and biosorption. Appl. Surf. Sci. 2017, 425, 728-735. [CrossRef]

22. Hernandez-Maldonado, J.A.; Torres-Garcia, F.A.; Salazar-Hernandez, M.M.; Hernandez-Soto, R. Removal of chromium from contaminated liquid effluents using natural brushite obtained from bovine bone. Desalin. Water Treat. 2017, 95, 262-273. [CrossRef]

23. Kyzas, G.Z.; Bikiaris, D.N.; Mitropoulos, A.C. Chitosan adsorbents for dye removal: A review. Polym. Int. 2017, 66, 1800-1811. [CrossRef]

24. Sudha, R.; Srinivasan, K.; Premkumar, P. Removal of nickel (II) from aqueous solution using Citrus limettioides peel and seed carbon. Ecotoxicol. Environ. Saf. 2015, 117, 115-123. [CrossRef]

25. Joaquín-Medina, E.; Patiño-Saldivar, L.; Ardilas-Arias, A.N.; Salazar-Hernández, M.; Hernández, J.A. Bioadsorption of methyl orange and methylene blue contained in water using as bioadsorbent Natural Brushite (nDCPD). Water Sci. Technol. 2021, in press.

26. Wang, X.S.; Zhou, Y.; Jiang, Y.; Sun, C. The removal of basic dyes from aqueous solutions using agricultural by-products. J. Hazard. Mater. 2008, 157, 374-385. [CrossRef]

27. Hernández-Soto, R.; Hernández, J.A.; Ardila-Arias, A.N.; Salazar-Hernández, M.; Salazar-Hernandez, C. The Use of Industrial Waste for the Bioremediation of Water Used in Industrial Processes. In Water Chemistry, 1st ed.; Eyvaz, M., Yüsel, E., Eds.; IntechOpen: London, UK, 2020; pp. 282-286.

28. Muñoz, B.E.L.; Robles, R.R.; García, J.L.I.; Gutiérrez, M.T.O. Adsorption of Basic Chromium Sulfate used in the Tannery Industries by Calcined Hydrotalcite. J. Mex. Chem. Soc. 2011, 55, 137-141. [CrossRef]

29. Kim, E.J.; Park, S.; Hong, H.J.; Choi, Y.E.; Yang, J.W. Biosorption of chromium (Cr (III)/Cr (VI)) on the residual microalga Nannochloris oculata after lipid extraction for biodiesel production. Biores. Technol. 2011, 102, 11155-11160. [CrossRef]

30. Nasernejad, B.; Zadeh, T.E.; Pour, B.B.; Bygi, M.E.; Zamani, A. Camparison for biosorption modeling of heavy metals (Cr (III), $\mathrm{Cu}$ (II), Zn (II)) adsorption from wastewater by carrot residues. Process Biochem. 2005, 40, 1319-1322. [CrossRef] 
31. Black, M.; Canova, M.; Rydin, S.; Scalet, B.M.; Roudier, S.; Delgado, L.-S. Best Available Techniques (BAT) Reference Document for the Tanning of Hides and Skins. Eur. Comm. Database 2013, 46, 2013. [CrossRef]

32. Uluozlu, O.D.; Sarı, A.; Tuzen, M.; Soylak, M. Biosorption of Pb(II) and Cr(III) from aqueous solution by lichen (Parmelina tiliaceae) biomass. Biores. Technol. 2008, 99, 2972-2980. [CrossRef]

33. Akhtar, N.; Iqbal, M.; Zafar, S.I.; Iqbal, J. Biosorption characteristics of unicellular green alga Chlorella sorokiniana immobilized in loofa sponge for removal of Cr (III). J. Environ. Sci. 2008, 20, 231-239. [CrossRef]

34. Bishnoi, N.R.; Kumar, R.; Kumar, S.; Rani, S. Biosorption of Cr (III) from aqueous solution using algal biomass spirogyra spp. J. Hazard. Mater. 2007, 145, 142-147. [CrossRef]

35. Bertagnolli, C.; da Silva, M.G.C.; Guibal, E. Chromium biosorption using the residue of alginate extraction from Sargassum filipendula. Chem. Eng. J. 2014, 237, 362-371. [CrossRef]

36. Mahmoud, M.E.; Mohamed, R.H.A. Biosorption and removal of $\mathrm{Cr}$ (VI)-Cr (III) from water by eco-friendly gelatin biosorbent. J. Environ. Chem. Eng. 2014, 2, 715-722. [CrossRef]

37. Carmona, M.E.R.; da Silva, M.A.P.; Leite, S.G.F.; Echeverri, O.H.V.; Ocampo-López, C. Packed bed redistribution system for $\mathrm{Cr}$ (III) and Cr (VI) biosorption by Saccharomyces cerevisiae. J. Taiwan Inst. Chem. Eng. 2012, 43, 428-432. [CrossRef]

38. Blázquez, G.; Hernáinz, F.; Calero, M.; Martín-Lara, M.A.; Tenorio, G. The effect of pH on the biosorption of Cr (III) and Cr (VI) with olive stone. Chem. Eng. J. 2009, 148, 473-479. [CrossRef]

39. Kobielska, P.A.; Howarth, A.J.; Farha, O.K.; Nayak, S. Metal-organic frameworks for heavy metal removal from wáter. Coord. Chem. Rev. 2018, 358, 92-107. [CrossRef]

40. Sing, K. Reporting physisorption data for gas/solid systems with Special Reference to the Determination of Surface Area and Porosity. Pure App. Chem. 1982, 54, 2201-2218. [CrossRef]

41. Chao, H.-P.; Chang, C.-C.; Nieva, A. Biosorption of heavy metals on Citrus maxima peel, passion fruit shell, and sugarcane bagasse in a fixed-bed column. J. Ind. Eng. Chem. 2014, 20, 3408-3414. [CrossRef]

42. Ngabura, M.; Hussain, S.A.; Ghani, W.A.; Jami, M.S.; Tan, Y.P. Utilization of renewable durian peels for biosorption of zinc from wastewater. J. Environ. Chem. Eng. 2018, 6, 2528-2539. [CrossRef]

43. Khasri, A.; Jamir, M.R.M.; Ahmad, M.A. Adsorbent from orange peel for Remazol Brilliant dye removal: Equilibrium and kinetic studies. AIP Conf. Proc. 2019, 2124, 020055. [CrossRef]

44. El Hamidi, A.; Mulongo Masamba, R.; Khachani, M.; Halim, M.; Arsalane, S. Kinetics modeling in liquid phase sorption of copper ions on brushite di-calcium phosphate di-hydrate $\mathrm{CaHPO}_{4} \cdot 2 \mathrm{H}_{2} \mathrm{O}$ (DCPD). Desalin. Water Treat. 2014, 56, 779-791. [CrossRef]

45. Khaskheli, M.I.; Memon, S.Q.; Siyal, A.N.; Khuhawar, M.Y. Use of orange peel waste for arsenic remediation of drinking water. Waste Biomass Valorization 2011, 2, 423. [CrossRef]

46. Reymond, J.P.; Kolenda, F. Estimation of the point of zero charge of simple and mixed oxides by mass titration. Powder Technol. 1999, 103, 30-36. [CrossRef]

47. Malook, K.; Ihsan-ul-Haque. Investigation of Aqueous Cr (VI) Adsorption Characteristics of Orange Peels Powder. Prot. Met. Phys. Chem. 2019, 55, 34-40. [CrossRef]

48. Sun, L.; Ma, Y.; Wang, H.; Zhu, T. Synthesis of florisil materials modified with aliphatic or aromatic groups and the application for pipette-tip solid-phase extraction of rutin in orange peel. J. Sep. Sci. 2018, 41, 3716-3723. [CrossRef] 